\title{
The Implementation of Mother Tongue-Based Multilingual Education: Seeing It from the Stakeholders' Perspective
}

\author{
John N. Cabansag ${ }^{1}$ \\ ${ }^{1}$ College of Arts and Sciences, Isabela State University, Echague, Isabela, Philippines \\ Correspondence: John N. Cabansag, College of Arts and Sciences, Isabela State University, Echague, Isabela, \\ Philippines. E-mail: johncabansag@ymail.com
}

Received: June 26, 2016

Accepted: July 26, 2016 Online Published: September 23, 2016

doi:10.5539/ijel.v6n5p43

URL: http://dx.doi.org/10.5539/ijel.v6n5p43

\begin{abstract}
Mother Tongue Based-Multilingual Education (MTB-MLE) has carved its niche as a practical and effective approach in the educational landscape. It offers a plausible framework for preparing coming generations to become better adaptive and even rich contributors in the globalized and intercultural world. The gate to the new millennium has brought great zeal in and at the same time contestations around this educational alternative.

This study examined the stakeholders' perspective on the implementation of MTB-MLE as a pedagogical approach. The stakeholders' perspective were explored and analyzed through the results of the different focus group discussions among teachers, pupils, parents, local school board, parents-teachers and community association, non-government organization and local government unit.

Results from this study indicate four main benefits of MTB-MLE, namely: expressing better ideas, building self-confidence, better retention, and promoting friendly environment.

Meanwhile, the challenges which hinder the implementation of MTB-MLE are grouped into four significant themes: multilingual environment, difficulty in translation, inadequacy of instructional materials, and mandatory compliance to the Department of Education (DepEd) order.

The significance of the results of this study points out important actions the program can benefit Filipino pupils. Notably, a system that emanated from the higher authorities in which grassroots sector were not consulted, the Department of Education (DepEd) order should be executed by an interface between the higher level management and the local stakeholders. Involving them can undoubtedly contribute in the success of MTB-MLE.
\end{abstract}

Keywords: MTB-MLE, medium of instruction, stakeholders' perspective, top-down approach

\section{Introduction}

Philippines have recently adopted the utilization of the first language of learners as a medium of instruction. Results of various researches as regards the benefits derived from using mother tongue instruction convinced the policy makers to adopt it in the educational system of the country. The benefits underscored in these researches include enhanced scholastic capability (Cummins, 2000; Thomas \& Collier, 1997; Walter \& Dekker, 2011); active involvement in the class (Benson, 2000; Dutcher, 1995); accessibility to instruction (Benson, 2004; Smits, Huisman \& Kruijif, 2008); and improved creative and critical thinking abilities (Brock-Utne, 2006). Studies also strengthened the relevance of multilingual education on the promotion and preservation of cultural heritage (Cummins, 2000; Wright \& Taylor, 1995); increased the active involvement of parents (Cummins, 2000; Dutcher, 1995; D'Emilio, 1995); and enhanced academic performance of female learners (Benson, 2005; Hovens, 2002).

Further, the result of a long term observational research conducted among first grade to third grade pupils in Lubuagan, an outskirt village of Cordillera Administrative Region in the Philippines on mother tongue based multi-lingual education bolstered its inception and usage in its educational system. This maiden study commenced in one school in 1999 and it was successfully started in 2005 with three schools in the experimental group and three in the control group. Evaluation was made after three years and it yielded consistent advantages in the learners in the mother tongue. They performed better than the learners in the control schools in English, Filipino, Reading, and Math (Walter \& Dekker, 2011). 
Along this vein, the dilemma on language policy in the Philippines is now being addressed by policy makers. As an archipelago consisting of more than 7000 islands and 181 different languages (Lewis, Simons, \& Fennig, 2013), the Philippines undoubtedly provides a stimulating educational setting for a successful implementation of a language policy that truly speaks of the needed language reforms and problems for over a hundred years in the country. These policies of language in the Philippines have evolved as a result of problems in politics, economy, and issues in culture at the local and national levels. Therefore, the country provides an avenue for researchers to delve on the top-down policy from the grassroots level stakeholders' perspective where pupils, teachers, administrators and parents are key factors in a clearer comprehension in the pursuit of MTB-MLE.

This study aims to offer ways in narrowing the gaps in both the postulatory and the actual differences surrounding the policy on mother tongue-based multi-lingual education. It explored on the bottom-up perception of teachers and parents in the midst of country's top-down reform. The theory on language policy states that corresponding actions of top implementers of language policy takes place when external elements decides without consulting those at the grassroots sector (Spolsky, 2004, 2011), on the contrary, deeper analysis and appreciation on the occurrence of language management seeing it from the perspective of grassroots sector should also be considered. While an increasing volume of researchers have seen the value of engaging grassroots sector in crafting policy on language (Shohamy, 2006; McCarty, 2011; Mohanty, Panda, \& Pal, 2010; Ricento \& Hornberger, 1996), there is still dearth of researches that look into the perspective of grassroots sector as regards the full implementation of mother tongue based multi-lingual education.

In terms of its relevance in the educational system and language-in-education policy, this study focusing on MTB-MLE answers the pressing issue for the presence of different languages in the Philippines that is working towards a well-defined policy on language. Further, this study is relevant considering that Philippines is left behind among its Southeast Asian neighbors to impose first language as medium of teaching in basic education much is still needed to know as to the ramifications to the country's concern especially in the grassroots sector. There is then a need to cascade the results of many researches and activities concerning the implementation of mother tongue education which were so successful worldwide to the grassroots sector. The researcher's evaluation of grassroots' perspective on the implementation of MTB-MLE will be the initial move in understanding this gigantic reform in the country's language policy. Pursuant to Section 4 and 5 of Republic Act No. 10533, basic education shall be delivered in languages understood by the learners as language plays a strategic role in shaping their formative years of learners. This novel reform in language policy introduces mother tongue as the language of instruction (LOI) and as a distinct course, carrying the descriptive title of teaching lessons in basic education using the first language of the learners. This will be utilized in teaching all subjects except Filipino and English from the first grade to the third grade. The feedback as regards the implementation of the program will inform policy makers in introducing the needed reforms to improve the process of refining it. Great lessons will be extracted from this study considering that it is evaluated after two years of its implementation.

\section{Methodology}

\subsection{Research Design}

Qualitative research design was utilized in this study because it focused on the experiences which are related to professional practices of stakeholders in implementing Mother Tongue Based-Multilingual Education (MTB-MLE). Specifically, these are the public school teachers, pupils, local school board, local government unit, parents and teachers association, non-government organization and parents.

One school district was the venue of the research using the embedded single-case design. An embedded case design comprises of analyzing subunits incorporated in the whole of the primary target of research (Yin, 2009). The different perception of the stakeholders served as the subunits of the study.

\subsection{Data Collection}

The focus group method was used because it presents a life-like environment in which the respondents were allowed to have group discussions about their perspectives on the implementation of MTB-MLE. A total of eleven (11) focus group discussions across selected stakeholders were conducted. This study complied with the requirement in conducting focus group discussion pegged at three FGDs in order to properly compare and contrast data across groups (Krueger \& Casey, 2009).

Semi-structured, open-ended questions were constructed based on the research questions. The guide questions for teachers were similar to those that were asked to the other stakeholders, except that there were additional questions to the teachers related to implementation. The questions were ordered in a logical sequence, from 
general questions to more specific or focused questions. In many cases, additional questions were asked to the focus group participants based on their responses.

\subsection{Research Site}

For the purpose of this study, two elementary schools at Echague West District, Echague, Isabela, Philippines were selected as the site of interest. Echague West Central School is located in the second largest municipality in the province of Isabela, Philippines. The school district covers a span of about 680.80 square kilometers, includes 64 barangays, and has a population of more than 67, 553 people. It has ten elementary schools and it is the largest of the three school districts in the municipality.

\subsection{Data Analyses}

Analysis began during the data collection period. Each day, the collected first-hand information were reviewed, synthesized, and documented in order to keep careful and detailed notes. Themes that emerged from focus group discussions were noted and analyzed comprehensively.

\subsection{Coding of Data}

Transcripts of the eleven (11) FGDs were coded using thematic content analysis as the main technique. Transcripts were analyzed following an incident-to-incident coding strategy, instead of a word-by-word or line-by-line coding strategy, in order to generate the main themes, sub-themes and categories, which were necessary in order to make sense of the participants' utterances. Further, the key-word-in-context (KWIC) method was utilized to come up with the different themes of the focus group discussion. To ensure the correctness of the transcription, textual data generated from the focus group discussions were transcribed verbatim from audio recordings and to a lesser degree, participant observation notes were also used.

\section{Results and Discussion}

The results of the focus group discussion reveal some congruencies and misalignments among stakeholders' perspective on the implementation of MTB-MLE. The conduct of a focus group discussion among teachers, parents, pupils, local school board, local government officials, parents-teachers and community association and non-government organizations is in consonance with the perception of various authorities on the subject who emphasized the active engagement of grassroots sector in making critical decision as regards policies affecting the country (Darling-Hammond, 1990; Elmore, 1983; Fullan, 2003).

After analysis of the stakeholders' views on the issue during the focus group discussion, four significant themes emerged on the stakeholders' perspective on the implementation of MTB-MLE: (1) expressing better ideas, (2) building self-confidence, (3) better retention, and (4) promoting friendly environment. On the other hand, the factors which hinder the implementation of MTB-MLE are divided into four significant themes: (1) multilingual environment, (2) difficulty in translation, (3) inadequacy of instructional materials, and (4) mandatory compliance to DepEd order.

\subsection{Stakeholders Perspective on the Implementation of MTB-MLE}

The implementation of mother tongue-based multi-lingual education (MTB-MLE) as viewed by the seven groups of stakeholders has elicited a rich output worth reflecting on for better results.

The Focus Group Discussions (FGDs) from different sectors representing the stakeholders in education emerged into two major themes relative to the implementation of MTB-MLE. The positive ideas sought represented the benefits in the use of mother tongue in the delivery of basic education for Grades 1,2, and 3 while the negative comments and observations represented the challenges in the implementation of this education reform in Philippine basic education. As shown in the figure, the flow of ideas depicts a battery that normally operates on two opposing sides to ignite the energy that is locked up. Hence, the conceptual model typifies the flow of energy that propels the MTB-MLE program to continue working for refinement of desired end results. 


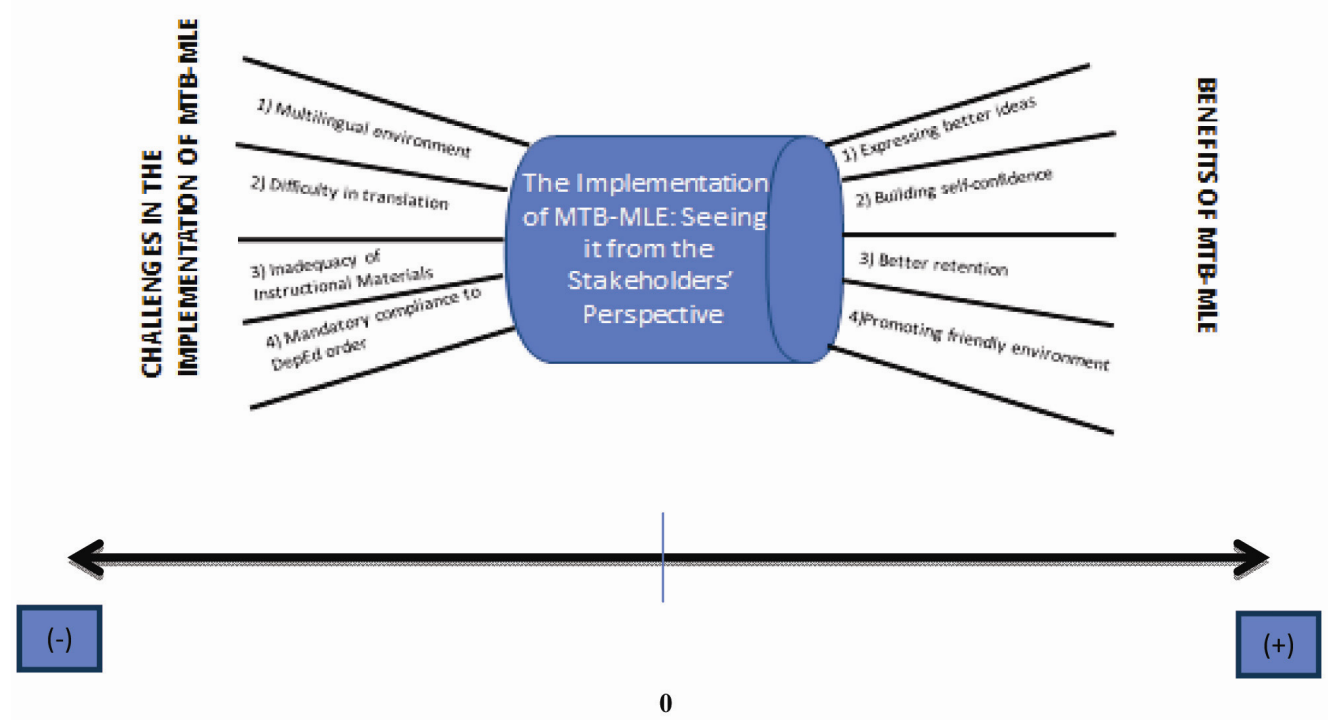

Figure 1. The benefits and challenges in the implementation of MTB-MLE

\subsection{Benefits of MTB-MLE}

\subsubsection{Expressing Better Ideas}

Most of the teacher-participants disclosed that the use of the mother tongue as medium of instruction for pupils in Grades 1 and 2 can facilitate better expression of ideas and understanding of lessons. Five teachers (T1, T2, T4, T6, T8) from the central school and two (T1, T3) from the barangay school noticed that the thoughts, feelings and understanding of pupils on the lesson are easily expressed using Tagalog. The use of Tagalog has aided functional understanding in Mathematics, i.e., learners can interpret the lessons delivered, and they can understand well how to compute numeric expressions. One statement from a teacher represented this perspective, "The DepEd issues an order using the mother tongue in order for the children or learners to easily understand lessons and for them to easily adopt what is to be learned and to be able for them to express their feelings, ideas or thoughts towards the lessons. For me, I use MTB or the susong wika in Tagalog because it is the only language wherein my pupils understand each other considering that my class is a mix of Yogad, Ilocano, and Tagalog."

The parents viewed that the government probably wants pupils to learn better and faster using mother tongue. The members of the Parents-Teachers and Community Association (PTCA) confirm the views of the pupils like listening to stories in Filipino and expressing their ideas easily. Representative of many parents' statements, one mother emphasized individual learning outcomes in her comment: "It's just all right with me to use mother tongue but it should be Tagalog instead of Ilocano."

The members of the Local School Board (LSB) represented by the School Principal and the District Supervisor affirm the use of Tagalog as medium of instruction to effect better comprehension of lessons; there is real understanding of what is read in Filipino compared to mere articulation of English sound but no real understanding of concepts. Similarly, the selected members of Non-Government Organization (NGO) and Local Government Unit (LGU) mentioned that mother tongue is good to use as medium of instruction because it can improve academic performance rooted from the ability of pupils to express their feelings and thoughts about the lesson. These perspectives of the three stakeholders were similar among most teachers, pupils, parents and non-government organizations (NGOs) who emphasized the value of mother tongue instruction for increasing students' understanding of lessons. One member of Local School Board (LSB) argued, "In Echague West Central School the children can easily understand the concept of what the teacher is explaining because they are well-versed with the dialect."

The findings of this study are aligned with the First Iloilo Experiment which was undertaken from 1948-1954 by 
Jose D. Aguilar who was a forerunner on the use of Hiligaynon as medium of instruction in Grades 1 and 2. The results revealed that Hiligaynon-taught children are far better than the English-taught children in reading, math and the social studies. The study affirmed that L1 pupils were able to transmit the knowledge learned in their L1 to English and the L1 pupils can cope with the L2 pupils in their knowledge of English within six months after being exposed to English as medium of instruction.

\subsubsection{Building Self-Confidence}

The meaningful lessons brought by understanding concepts delivered in the mother tongue empowered the pupils to develop self-confidence and more active participation in class work (T5, T10). The teacher-participants revealed that the use of the mother tongue in class allowed the pupils to freely express their answers. One teacher described this viewpoint: "By the time children begin school, they have begun gaining confidence in their ability to communicate meaningfully in their mother tongue".

A grade 2 pupil (P4) admitted that there can be no fear when reciting in class using the Filipino language. Consistent with this claim, a parent-respondent $(\operatorname{Pr} 4)$ shared that when the language used in class was changed from Ilocano to Tagalog which is the mother tongue of her child, there was a change in the level of self-confidence of the child in class participation. One pupil in this category said "I'm not afraid to talk and participate in recitation."

In addition, the classroom experience of a teacher-participant (T2) shared during a focus group discussion with PTCA members helps prove the increased self-confidence of learners in class using mother tongue, particularly Tagalog, as a medium of instruction. He stated "If stories are told in Filipino, the pupils listen attentively and almost all the learners want to speak out their ideas and react to questions". A member of an NGO (NGO10) has also affirmed the increased self-confidence of her child in class using mother tongue as evidenced by the child's consistent active participation. This recurrent theme was evident in the focus group discussions among the members of the Local School Board (LSB) and local government officials. For example, one member of the Local School Board (LSB) stated, "The children are confident in communicating. They can even talk with their parents about the lessons in the school which is very important in the educational process".

Carefully planned MTB-MLE programs facilitate students to build a firm educational foundation when they 1) enable and encourage pupils to develop oral fluency in their L1;2) introduce reading and writing in the L1; help pupils to become fluent and confident in L1 literacy; and 3) build their capacity to use the L1 for everyday communication and for learning in school (Malone, 2007).

\subsubsection{Better Retention}

A teacher-participant (T1) and a school principal who is also a member of the Local School Board (LSB) found the use of mother tongue as medium of instruction to result in better retention of lessons. They explained that when lessons are understood like in Mathematics, the concepts will be easily recalled when situations call for it. The Tagalog or Filipino language as mother tongue is used as the medium of instruction in MTB-MLE subject field, Araling Panlipunan, Edukasyong Pagpapakatao, MAPEH, Mathematics, and the Filipino subject. Teachers and members of the Local School Board (LSB) shared the same perception by stating, "The impact is very interesting like in Mathematics; the pupils enjoy because they understand the concepts. It becomes enjoyable to them unlike before that they use English and only few understand it." Some pupils in grades 1 and 2 reported repetition of topics in MTB-MLE and in Filipino as subject fields, i.e., they noticed that there are similarities of concepts presented in the two courses although the former focuses on reading while the latter on language. A teacher in the central school (T11) and PTCA members (Teacher 2, and Parent 1) presented the observation from pupils on the repeated topics in the two subject areas. The variation of lesson presentation does not conceal the similarities.

Students can easily understand and retain lessons taught in mother tongue, thus making them more productive not only on a personal scale but on a wider scope. Children whose first language is not used at school...experience lower levels of learning and are much less likely to be able to contribute to a country's economic and intellectual development (World Bank, 2006, p. 4). One Local Government Unit (LGU) officer mentioned that "Children beginning to learn how to read and write using their mother tongue are more confident, more dynamic, and most likely successful in school and therefore become truly bilingual, undoubtedly proficient in both their first language and the national language, thus more active participants in, and catalysts to national development. If parents are appreciative and understand the lessons of their children in school, they become instruments in cultivating strong motivation of their children in studying and keeping their children in school." 


\subsubsection{Promoting Friendly Environment}

Learners in grades 1 and 2 display distinct behaviors in school such as having short attention span, easily moved by emotion such as excitement, fear, anger, or being shy. The experiences during the early years in school can bring significant influences on the learners' outlook on studies, on career and on life. Promoting a friendly teaching-learning environment must be one among the important tasks teachers perform. Encouraging a child to talk in class begins with allowing a child to speak in his/her mother tongue. Teacher-participants (T1, T2, T3), a PTCA member (T2), an NGO member (NGO3) and the school administrators (Principal and District Supervisor) as members of the local school board have consistent accounts on the effect of mother tongue as a medium of instruction in building a suitable learning atmosphere. They declared, "When the pupils enter the portals of the classroom carrying with them insights on the first language they will be able to understand better, enjoy more and will be highly motivated to attend classes because they can understand the language inside the classroom". One member of the Local School Board (LSB) mentioned "the impact is very interesting like in Mathematics the pupils enjoy because they understand the concepts. It becomes enjoyable to them unlike before that they use English and only few understand it".

The classroom teachers having direct contact with pupils in grades 1 and 2 consider mother tongue as an important tool in honing pupils' abilities in speaking, listening, reading, and writing and teachers themselves feel comfortable delivering lessons using Tagalog or Filipino. The ease of expression both by the teacher and learners result in gaining more comprehension on lessons and more participation in class. A PTCA member shared an observation on a learner's excitement to speak out an idea about a story read in Filipino language. Satisfying school experiences make learners become interested in their studies and persevere more (NGO3). In addition, school administrators noted the reduced cases of pupil drop-outs because they no longer feel alienated in the classroom unlike the cases of previous years when pupils in classrooms were exposed to foreign language in the delivery of lessons. This supports the findings of World Bank in 2005 stating that fifty percent of the world's out-of-school children live in communities where the language of schooling is rarely, if ever, used at home. This underscores the biggest challenge in achieving Education for All (EFA), a legacy of non-productive practices that lead to low levels of learning and high levels of dropout and repetition.

A positive learning atmosphere where learners and teachers feel comfortable with the overall language use creates a successful literacy. Dynamism in learning improves self-esteem and motivation to attend school. Stress and anxiety destroy learning and research discloses that teachers quickly resort to threatening measures when they deliver lessons in less familiar languages (Ouane, 2003).

\subsection{Challenges in the Implementation of MTB-MLE}

The perceived challenges of a reform may affect its ability to be implemented at the ground level. Stakeholders' general views of these challenges were reflected in their perceptions of the feasibility of classroom implementation. Four main themes were uncovered in the data related to these challenges. These included the multilingual environment, difficulty in translation, inadequacy of instructional materials and mandatory compliance to DepEd order.

\subsubsection{Multilingual Environment}

A challenge to the implementation of mother tongue-based instruction is the multilingual environment. A teacher (T8) cited her class as a mix of different languages such as Ilocano, Yogad, Ibanag, \& Tagalog so she has to use Tagalog as the mother tongue that is commonly understood by all her pupils. She expressed this viewpoint: "I am using Tagalog in my classroom because my pupils are Ilocano, Yogad and Ibanag." Children whose first language is other than Tagalog do not really get instruction in their first language while the policy requires the use of mother tongue exclusively for the first three grade levels. An attempt to use Ilocano as medium of instruction has been done by a teacher-participant (T10) in a central school but parents (P1, P4, P5, P6, P7) whose children could not understand Ilocano complained so the teacher has to shift to Tagalog or Filipino that the children can commonly communicate. This recurrent theme was evident in all of the focus group discussions. For example, one teacher stated "MTB facilitates class participation because they can easily express their ideas than in English. Before I started teaching, I told my class I want to teach using Ilocano."

The multilingual environment is a problem on the strict compliance of the mother tongue-based instruction policy not only on the part of the learners but also on the part of teachers who cannot speak well the first language of their class. The commonly sought solution to the problem is to use the national language that is Filipino or Tagalog. 


\subsubsection{Difficulty in Translation}

Translating lesson content in the local languages and even the dialects as a way of addressing the use of mother tongue for non-speakers of Tagalog is a big challenge to teachers. An experience of a barangay school teacher (T2) illustrates this, such that Filipino or Tagalog is used as mother tongue but in an event of unfamiliar Filipino terms are used in the lesson, she has to translate in the Yogad language. One teacher expressed with frustration, "Our mother tongue here is Filipino but when we encounter unfamiliar terms we translate in the Yogad language." The research locale in the town of Echague, Isabela is known as a Yogad speaking place but societal mobility and intermarriages resulted in the use of several languages and even dialects such as varieties of Ibanag and Ilocano by the residents but which are not familiar to some teachers in the place. It creates a big challenge on the part of the teacher to speak in the different first languages spoken by her pupils. One teacher explained, "We were told in a seminar that if the teacher is Ilocano and the majority of the pupils are Tagalog then they should be taught in Filipino. There is no use talking in Ilocano if the pupils cannot understand it."

Another compounding problem on academic language is on lessons that create impractically longer terminologies like in counting numbers and place value chart spoken in Filipino. A teacher-participant (T9) recalled terms in Mathematics spoken in Tagalog as lengthy or wordy. The teacher stated, "For me in Grade 2, I use mother tongue in all subjects except in English. At first, I encountered difficulty in teaching Mathematics like those lessons in place value chart translating ones, tenths, hundredths including counting numbers. But on the part of the learners the use of mother tongue in teaching Mathematics makes them easily understand the lesson."

Surprisingly, a number of grade 1 pupils in a central school prefer English as the medium of instruction so that they can communicate with English speaking children or peers (Pu1, Pu2, Pu3, Pu4). This challenge may be attributed to their earlier exposure in the English language such as in their use of the internet; they frequent you tube, video games, and the cartoons. Four pupils were confident in their statements: Pu 1: "English..."; Pu2: ... so that I know how to speak English"; Pu 3: "English...I prefer English because I can use it when I talk to an American kid like me..."; and, Pu 4: "I like English". Similarly, one top ranking local government official mentioned that English should be the medium of instruction considering the global prevalence of English. It is widely apparent among teachers and parents that they desire pupils to gain skills in English. In particular, knowledge of English is usually equated with privilege and the opening of opportunities. She stated, "Learning the mother tongue is only good in the place where the pupils live but learning the English language or Mandarin will be advantageous on the part of the pupils because in our world today English or Mandarin is the language of multinational companies or the business world. If you use English, chances are you will be able to communicate to the rest of the world." These perceptions of stakeholders emphasized the relevance of possessing the command of the English language. On the contrary, they also posed their reluctance on the significance of MTB-MLE in developing the English language communication skills of learners.

This result confirms the findings of Sibayan (1999) that these perceptions of English endured up to the 21st century in which speakers of indigenous language experience low self-esteem and cling to their hopes of using English as a language to be used in the four-walls of the classroom. All of them strongly urge that English brings bright future in their lives. As Williams \& Cooke (2002) claim, "People view the language as a 'powerful' medium towards landing a decent and high paying job." English is also associated with economic value making it a priority in the learning of the majority to the detriment of indigenous languages (Hornberger \& Vaish, 2009; Ricento \& Hornberger, 1996).

\subsubsection{Inadequacy of Instructional Materials}

The most commonly raised issue by the stakeholders on the implementation of MTB-MLE is the unavailability or inadequacy of textbooks and learning materials that can facilitate the proper delivery of the program (T1, T2, T3 in a barangay school; LSB; PTCA, NGO, LGU, etc). The government did not provide materials right after the issuance of a memorandum on the implementation of MTB-MLE; instead, Department of Education authorities gave curriculum guides embedded with the core competencies during the week three of classes. After that, principals received learning packages with lessons incorporated in it as well as worksheets for pupils. But teachers lamented because they had to reproduce these materials at their own expense. Further, the teachers and administrators professed that the scarcity of teaching materials affected their delivery of instruction. Based on the claim of one teacher and member of the Local School Board (LSB):

\section{T1: "After my training I was given CD and the Division Personnel told me to reproduce it."}

LSB 1: "A seminar should be conducted in the national level and it will be cascaded to the division level. After the seminar, instructional materials should be given to the teachers because without these learning materials parents and teachers will have difficulty in assisting the pupils in their lessons in the class." 
The MTB-MLE program has not been criticized as regards its relevance to instruction, but the availability of needed instructional materials poses great challenge in its right execution. Despite MTB-MLE's popular claims of success, Dutcher (2003) posited that essentially the program is fruitless when there are scanty teaching materials, inferior teacher training, and deficient language development. Ambatchew (2010) argued that "unless adequate learning materials like books, ICTs, software, print and broadcast media are provided in the medium or media of instruction, the pupils are threatened to failure". While it is true that learning materials are being supported by non-government organizations, it is lamentable to note that this is only limited to some places. Ironically, the support to the program given by these groups surpassed what the national government had provided (Bloch, Guzula, \& Nkence, 2010).

The Department of Education prepared modules and instructional guides in Ilocano and Filipino languages for the Cagayan Valley region. However, these resources were not given on time and there are schools that obtained only the soft copy of instructional materials stored in CD.

Instructional materials in Ilocano language given to a teacher (T10) has been used only for a short time because parents $(\operatorname{Pr} 1, \operatorname{Pr} 4, \operatorname{Pr} 4 . \operatorname{Pr} 5, \operatorname{Pr} 6, \operatorname{Pr} 7)$ complain of the difficulties their children experienced in understanding their lessons in Ilocano. The waiting time for replacement brought another challenge on the issue. With the complexity of concerns and issues in addressing the issue, majority of the stakeholders have bright prospects for the successful implementation of the MTB-MLE program.

\subsubsection{Mandatory Compliance to DepEd Order}

The stakeholders stated that the DepEd order must be implemented because it is a national policy in the education sector. They have explained that their compliance to the program means the attainment of its goals and objectives. This repeated thesis dominated all the stakeholders' discussions. For example, one teacher stated, "We claim that MTB-MLE is good for mastery. But at first we were negative about its impact to us and because it is already implemented, we think that it is just proper to speak of its positive result". Numerous stakeholders echoed these teachers' sentiments. One Local School Board (LSB) said, "If the teachers do not support MTB-MLE what will happen to the program? The teachers must support it because that is an order from the higher authorities, they cannot do otherwise. By all means they have to learn the language."Another member of the Local School Board mentioned that, "it was a top-down implementation... although the program is good...I like it." These quotes clearly manifest strong concurrence to the top down DepEd policy that tends to undermine even teachers' own belief system. This is seen in the all-out support of teachers and stakeholders to the DepEd order because it emanated from the top level management. This stereotype perception of teachers to the top-down approach promotes a culture of compliance among local stakeholders in which they treat themselves as obedient followers of issued orders from the powers that be (Hoyle \& Wallace, 2007; Shohamy, 2006). Further, teachers explicitly seen as "devoted follower", that is, they sincerely implement rules (Shohamy, 2006). This goes to show that they engage themselves in self-introspection on the implications of the policies according to their views and exposure to the world (Silver \& Skuja-Steele, 2005). Their mode of implementing it in the grassroots sector is actually keeping it according to the atmosphere and dictate of local language ideologies (Johnson \& Freeman, 2010).

Apparently, the teachers exhibit their opposition to the program by way of introducing modifications in their delivery of lessons so as to conform to the practices in the classroom. This is demonstrated in the following comments of one teacher, "In my English subject, I also translate in Filipino". It came out that the uniform venue of reluctance is found in Math classes. Most of the teachers switched to English equivalent in order to clearly explain the concepts to the learners. In reality, teachers encountered difficulty explaining the precise Filipino or Ilocano terminology for Math concepts. The following view of a teacher represents his difficulty and resentment of translating the concepts in Mathematics: “...because Math is taught in English in the past, now it is taught in Filipino. There are terms that we couldn't translate in the mother tongue so they couldn't understand. Then, in their English reading process, they are hard up...Grade 1 pupils used to have learned several terms already unlike these pupils these days."

This manifests the adjustments done by teachers in the classroom in order to satisfy the DepEd order and deliver the needed services to the learners. Generally, these actions exhibit the strategies of the teachers in differentiating an order against their views of its results.

Despite stakeholders' concurrence in their perceptions about MTB-MLE outcomes, lesser interactions occur between groups. It means that actions supporting and resisting MTB-MLE were done in separate ways of influence. Teachers focused their activity to the classroom, and other related contexts, while parents concentrated in the home, local school board shared in the successful implementation of the program, local government unit 
provides the needed information and communications technology and human resource by allocating salary for local school board teachers, non-government organizations, parents-teachers and community association support to school projects and activities. It is a truism that many studies underscored the participation of the grassroots sector in crafting language policies (Chimbutane \& Benson, 2012; Dekker \& Young, 2005), grassroots sector manifested distinct behavior and perceptions on the issue. This situation proves the real characteristics of a top-down process in which orders directly originated from outside against a bottom-up approach where a directive stems from the individuals within the system.

\section{Conclusion}

This research was conducted purportedly to provide additional information and inputs on the implementation of Mother Tongue-Based Multi-Lingual Education (MTB-MLE) program.

While the stakeholders spoke of conformity and presented honest statements of support for the policy, they also expressed skepticism about the significance of the program to the pupils. Their inner beliefs and actions of renitence in the classroom and homes appeared in contrast to the apparent compliance to the policy guidelines. This exhibits a difference between the inner and apparent nature of policy. There is no assurance that a policy will be implemented successfully by the mere issuance of a directive. It then creates a challenge among outsiders to sincerely grasp the real scenario at the ground level because teachers and parents are accustomed to presenting an image of compliance. The involvement of local stakeholders in the planning process can reduce the vagueness the actual implementation of a national policy at the ground level.

In addition, the stakeholders' discussion on the implications of MTB-MLE on the participation of students in the classroom and its impact to their learning as a whole is affected by their long-held views of English as the desired language. It then rendered their fear that the policy would only cultivate lower English skills among the learners despite their positive responses toward MTB-MLE during the focus group discussions.

Further, the results of this study can provide rich information on the processes involved in formulating language policy which are pursued in various multilingual settings. In addition, the results of this study provide the relevance of scrutinizing the procedures in which important partners comprehend and legislate policies on language. Two important issues were highlighted and deduced in this research: the advantages of MTB-MLE instruction and the challenges that impede its successful implementation.

Ultimately, wisdom, experiences and perspectives of local stakeholders can amply contribute to the successful implementation of the MTB-MLE program.

\section{References}

Ambatchew, M. D. (2010). Traversing the linguistic quicksand in Ethiopia. In K. Menken \& O. Garcia (Eds.), Negotiating language policies in schools: Educators as policymakers (pp. 211-231). New York: Routledge.

Benson, C. (2000). The primary bilingual education experiment in Mozambique, 1993 to 1997. International Journal of Bilingual Education and Bilingualism, 3(3), 149-166.

Benson, C. (2004). The importance of mother tongue-based schooling for educational quality. Background paper for EFA Global Monitoring report 2005. Paris: UNESCO.

Benson, C. (2005). Girls, educational equity and mother tongue. Bangkok: UNESCO.

Bloch, C., Guzula, X., \& Nkence, N. (2010). Towards normalizing South African classroom life: The ongoing struggle to implement mother-tongue based multilingual education. In K. Menken \& O. Garcia (Eds.), Negotiating language policies in schools: Educators as policymakers (pp. 88-106). New York: Routledge.

Burton, L. A. (2013). Mother Tongue-Based Multilingual Education in the Philippines: Studying Top-Down Policy Implementation from the Bottom Up. University of Minnesota.

Chimbutane, F., \& Benson, C. (2012). Expanded spaces for Mozambican languages in primary education: Where bottom-up meets top-down. International Multilingual Research Journal, 6(1), 8-21. http://dx.doi.org/10.1080/19313152.2012.639278

Cummins, J. (2000). Language, power and pedagogy: Bilingual children in the crossfire. Clevedon, England: Multilingual Matters.

D'Emilio, L. (1995). Education and the Indigenous peoples of Latin America. In ICDC/UNICEF, Children of minorities: Deprivation and discrimination (pp. 77-88). Florence, Italy: UNICEF

Darling-Hammond, L. (1990). Instructional policy into practice: The power of the bottom over the top. Educational Evaluation and Policy Analysis, 12(3), 339-347. 
Dekker, D., \& Young, C. (2005). Bridging the gap: The development of appropriate strategies for minority language communities in the Philippines. Current Issues in Language Planning, 6(2), 182-199.

Dutcher, N. (1995). The use of first and second languages in education. A review of international experience. Pacific Island Discussion paper Series No. 1. Washington, DC: World Bank.

Dutcher, Nadine in collaboration with Richard Tucker. (1994). The use of first and second languages in education. A review of international experience. Pacific Islands discussion paper series no. 1. Washington D. C.: The World Bank.

Elmore, R. (1983). Complexity and control: What Legislators and administrators can do about implementing policy. In L. S. Shulman \& G. Sykes (Eds.), Handbook of Teaching and Policy. NY: Longman.

Fullan, M. (2003). The new meaning of educational change. New York: Teachers College Press.

Hornberger, N. (2002). Multilingual language policies and the continua of biliteracy: An ecological approach. Language Policy, 1, 27-51. http://dx.doi.org/10.1023/A:1014548611951

Hornberger, N., \& Vaish, V. (2009). Multilingual language policy and school linguistic practice: Globalization and English-language teaching in India, Singapore and South Africa. Compare, 39(3), 305-320.

Hovens, M. (2002). Bilingual education in West Africa: Does it work? International Journal of Bilingual Education and Bilingualism, 5(5), 249-266.

Hoyle, E., \& Wallace, M. (2007). Educational reform: An ironic perspective. Educational Management Administration and Leadership, 35(1), 9-25.

Johnson, D. C., \& Freeman, F. (2010). Appropriating language policy on the local level: Working the spaces for bilingual education. In K. Menken \& O. García (Eds.), Negotiating language policies in schools: Educators as policymakers (pp. 13-31). New York: Routledge.

Krueger, R., \& Casey, M. A. (2009). Focus groups: A practical guide for applied research. Los Angeles: Sage.

Lewis, P., Simons, G., \& Fennig, C. (Eds.). (2013). Ethnologue: Languages of the world (17th ed.). Dallas, Texas: SIL International. Retrieved from http://www.ethnologue.com

Malone, S. E. (2010). SIL International, Mother tongue-based multilingual education current challenges and some strategies for moving forward. Multilingual Education Conference, Jomo Kenyatta University, Nairobi, Kenya.

McCarty, T. (2011). Introducing ethnography and language policy. In T. Mc Carty (Ed.), Ethnography and language policy (pp. 1-28). New York: Routledge.

Menken, K., \& Garcia, O. (Eds.). (2010). Negotiating language policies in schools: Educators as policymakers. New York: Routledge.

Merriam, S. B. (1998). Qualitative research and case study applications in education. San Francisco: Jossey-Bass.

Mohanty, A., Panda, M., \& Pal, R. (2010). Language policy in education and classroom practice in India: Is the teacher a cog in the policy wheel? In K. Menken \& O. Garcia (Eds.), Negotiating language policies in schools: Educators as policymakers (pp. 211-231). New York: Routledge.

Ouane, A., \& Christine, G. (2014). Mother Tongue Literacy in Sub-Saharan Africa. UNESCO Institute for Education. Retrieved from portal.unesco.org/education/en/files/43180/11315379981Ouane_A.doc/

Philippines Department of Education. (2009). Institutionalizing mother tongue-based multilingual education (Order no. 74). Pasig City: Author.

Philippines Department of Education. (2012). Guidelines on the implementation of the mother tongue-based multilingual education (MTB-MLE) (Order no. 16). Pasig City: Author.

Ricento, T., \& Hornberger, N. (1996). Unpeeling the onion: Language planning and policy and the ELT professional. TESOL Quarterly, 30(3), 401-427.

Shohamy, E. G. (2006). Language policy: Hidden agendas and new approaches. New York: Routledge.

Sibayan, B. P. (1999). The intellectualization of Filipino. Manila: Linguistic Society of the Philippines.

Silver, R. E., \& Skuja-Steele, R. (2005). Priorities in English language education policy and classroom implementation. Language Policy, 4, 107-128. 
Smits, J., Huisman, J., \& Kruijff, K. (2008). Home language and education in the developing world. Background paper for EFA Global Monitoring 2009. Paris: UNESCO.

Spolsky, B. (2004). Language policy. Cambridge: Cambridge University Press.

Spolsky, B. (2011). Language management. Cambridge: Cambridge University Press.

Spolsky, B., \& Shohamy, E. (2000). Language practice, language ideology, and language policy. In R. Lambert \& E. Shohamy (Eds.), Language policy and pedagogy: Essays in honor of A. Ronald Walton (pp. 1-42). Amsterdam: John Benjamins Publishing Company.

Stake, R. (2000). Case studies. In N. K. Denzin \& Y. S. Lincoln (Eds.), Handbook of qualitative research (pp. 435-454). Thgousand Oaks, CA: Sage.

Stake, R. E. (2005). Qualitative case studies. In N. K. Denzin \& Y. S. Lincoln (Eds.), The Sage handbook of qualitative research (pp. 443-466). Thousand Oaks, CA: Sage.

Thomas, W. P., \& Collier, V. P. (1997). A national study of school effectiveness for language minority students' long- term academic achievement.George Mason University, CREDE (Center for Research on Education, Diversity \& $\quad$ Excellence). $\quad$ Retrieved from http://www.usc.edu./dept/education/CMMR?CollierThomasComplete.pdf

Thomas, W., \& Virginia, C. (1997). School effectiveness for language minority students. National Clearinghouse for Education. Retrieved from http://www.crede.ucsc.edu/research/llaa/1.1_final.html

UNESCO. (1953). The use of vernacular language in education. Monograph on Fundamental Education. Paris: UNESCO.

UNESCO. (2003). Education in a multilingual world. UNESCO Education Position Paper. Paris: UNESCO. Retrieved from http://unesdoc.unesco.org/images/0012/001297/1297/129728e.pdf

UNESCO. (2007). Mother tongue-based literacy programmes: Case studies of good practice in Asia. Bangkok: UNESCO Asia and Pacific Regional Bureau for Education.

UNICEF. (1999). The state of the world's children, 1999. New York: Author.

Walter, S., \& Dekker, D. (2011). Mother tongue instruction in Lubuagan: A case study from the Philippines. International Review of Education, 57(5-6), 667-683.

Williams, E., \& Cooke, J. (2002). Pathways and labyrinths: Language and education in development. TESOL Quarterly, 36(3), 297-322.

Wright, S. C., \& Taylor, D. M. (1995). Identity and the language of the classroom: Investigating the impact of heritage versus second language instruction on personal and collective self-esteem. Journal of Educational Psychology, 87, 241-252. http://dx.doi.org/10.1037/0022-0663.87.2.241

\section{Copyrights}

Copyright for this article is retained by the author(s), with first publication rights granted to the journal.

This is an open-access article distributed under the terms and conditions of the Creative Commons Attribution license (http://creativecommons.org/licenses/by/4.0/). 